\title{
Condiciones físico-ambientales de la localización espacial de los nuevos asentamientos rurales: Región del Maule
}

\author{
Margarita Riffo Rosas \\ Departamento de Geografía, Facultad de Arquitectura y Urbanismo. \\ Universidad de Chile. \\ mriffo@uchilefau.cl \\ Pamela Castro Osorio \\ Departamento de Geografía, Facultad de Arquitectura y Urbanismo. \\ Universidad de Chile \\ pamcastr@uchile.cl \\ Carol Retamales Villa \\ Escuela de Geografía, Universidad de Chile. \\ cretavil@gmail.com \\ Laura Malermo Guajardo \\ lauramalermo@gmail.com
}

RESUMEN

\begin{abstract}
Este artículo informa acerca de algunos de los resultados obtenidos del Proyecto de Investigación DI- U. Chile MULT 04/29-2 (2005-2006). En esta oportunidad se analizan las condiciones físico-ambientales de la localización espacial de los villorrios agrícolas conformados con apoyo del Programa de subsidio habitacional del Estado en tres comunas de la región del Maule. Para ello se consideran tres variables de contexto: la red hídrica, la pendiente y la aptitud de los suelos, utilizando como base la cartografía regular del Instituto Geográfico Militar, el listado de villorrios de cada municipio y su constatación en terreno, junto con la aplicación de entrevistas y la información sobre la normativa legal pertinente al tema.
\end{abstract}

Palabras Clave: Asentamientos rurales, Localización Espacial, Vulnerabilidad.

\section{Fisical and environmental conditions of the new rural settlement spacial localization:maule region}

\begin{abstract}
This paper reports some of the results reached by the Research Project DI-U Chile MULT 04/29-2 $=(2,005-2006)$. In this opportunity, the physical and environmental conditions of the spatial localization of agricultural villages are analyzed. These villages were formed with the support of State Housing Subsidies Program carried on in three municipalities of the Maule Region. For this subject were considered three context variables: the drainage net, the slope and the soils aptitude, using has cartographic base the topographic regular charts of the Military Geographical Institute, the list of villages in each municipality, its existence and localization checking, joint with interviews and the information over pertinent legal regulations.
\end{abstract}

Key words: Rural settlements, Spatial localization, Vulnerability 


\section{INTRODUCCIÓN}

En la evolución del sector rural chileno, su estructura y funcionalidad ha estado determinada por factores externos de acuerdo al rol que le ha correspondido desempeñar en la economía nacional.

Así, en el período de Industrialización sustitutiva ejerció un rol subsidiario aportando materias primas, alimentos y mano de obra al desarrollo de dicha actividad localizada en áreas urbanas, junto con contribuir al crecimiento de las ciudades con el aporte migratorio de la población rural. En dicho contexto, el espacio rural se estructura en torno a las actividades silvoagropecuarias preferentemente, mientras el patrón de poblamiento predominante era el disperso, basado en la distribución espacial del sector campesino, junto con algunos núcleos de concentración, representados por caseríos, aldeas y pueblos que funcionaban como centros de servicios para el sector.

En la actualidad y en el contexto de la Globalización y la modernización productiva, el sector rural es valorizado externamente por sus ventajas comparativas naturales para producir bienes exportables, atrayendo inversiones de origen nacional e internacional y generando nuevos empleos básicamente de tipo temporal, determinado por la expansión de la fruticultura y silvicultura y el retroceso de la agricultura tradicional.

Posteriormente, el espacio rural es valorizado además como "un lugar para vivir"por parte de pobladores de ingresos medio-altos y de origen urbano, los que a través del fenómeno de las llamadas "parcelas de agrado y condominios"localizan su residencia permanente en áreas rurales.

Junto con ello, los pobladores de origen rural y de bajos ingresos son retenidos en sus áreas de origen, reduciendo con ello el éxodo rural mediante la conformación de nuevos asentamientos rurales denominados "villorrios"por sus habitantes, los que han surgido especialmente en áreas de modernización productiva con el apoyo del Estado a través de su Política de Subsidio Habitacional y la acción de los propios pobladores organizados para postular en los concursos respectivos del Ministerio de Vivienda y Urbanismo (MINVU).

Como resultado, se constata por una parte, un proceso creciente de re-asentamiento de la población rural en núcleos de concentración dispersos que rompen con el patrón tradicional de poblamiento rural, y por otra, una competencia gradual entre el uso productivo y el uso residencial del suelo (donde participan también las parcelas de agrado y condominios), afectando incluso la disponibilidad de suelos de aptitud agrícola.

La problemática que se presenta en este trabajo, dice relación con el diferente significado de estos procesos en el espacio rural, por cuanto mientras la localización espacial y el nivel constructivo de las parcelas de agrado y condominios no tiene efectos colaterales negativos para sus residentes, quienes contribuyen a su financiamiento en forma privada, la localización de los villorrios rurales es definida por el valor comercial del suelo que puede ser cubierto por los pobladores rurales de bajos ingresos, dando como resultado que gran parte de ellos se emplaza en áreas de riesgo, principalmente de inundación, frente a lo cual el nivel constructivo de las viviendas sociales y la infraestructura de apoyo, contribuye a agravar el problema de vulnerabilidad de estos conjuntos residenciales.

Junto con esta problemática que afecta la sustentabilidad ambiental de los nuevos asentamientos rurales y con ello la calidad de vida de sus habitantes, la ocupación de suelos de aptitud agrícola para fines residenciales que restringe el uso productivo, es otra dimensión del proceso de relocalización espacial de la población rural. 


\section{MATERIALES Y MÉTODOS}

La Región del Maule fue seleccionada considerando su alto Índice de Ruralidad (33,6\% según Censo 2002), y su importancia frutícola a nivel nacional, ocupando el tercer lugar en jerarquía con 54.749 há. según VII Censo Nacional Agropecuario de 2007.

Como áreas específicas de estudio fueron seleccionadas tres comunas de la Provincia de Curicó (la que a su vez presenta mayor especialización frutícola a nivel regional): una comuna fuertemente urbanizada (Curicó, con solo $16 \%$ de ruralidad en 2002) y dos comunas altamente ruralizadas (Sagrada Familia y Romeral, ambas con un $71 \%$ ). Las unidades de análisis específico son los villorrios agrícolas existentes en las tres comunas (63 en total) que han sido conformados con el apoyo del Programa de Subsidio Habitacional Rural del Ministerio de Vivienda y Urbanismo (MINVU).

En la primera parte del estudio, se analiza la normativa legal que interviene en la formación de los villorrios agrícolas, considerando el Reglamento del Programa de Subsidio Habitacional Rural (MINVU) y la Ley General de Urbanismo y Construcciones (artículo 55) que reglamenta la construcción de conjuntos habitacionales de viviendas sociales en áreas rurales. En la segunda parte, se analizan los factores físico-ambientales de la localización espacial de los villorrios, considerando tres variables de contexto: la Red Hídrica, la Pendiente y la Aptitud de los Suelos. Para ello, se utilizó como material de base las Cartas Regulares del Instituto Geográfico Militar a escala 1:50.000 y 1:25.000; el Listado de villorrios comunales proporcionado por los respectivos municipios y su constatación y localización en terreno con GPS; como referente se utilizó la Clasificación de Usos según Rango de pendientes del State Survey of Kansas, aplicada por el MOPT y finalmente, la Clasificación de Uso Potencial del Suelo del SINIA (Sistema Nacional de Información Ambiental).

\section{MARCO TEÓRICO}

\section{Globalización de la Economía, Moderni- zación Rural y Urbanización del Campo}

Una de las grandes transformaciones ocurridas en las últimas décadas en la Economía mundial está orientada por el denominado proceso de Globalización, el cual se impone a escala planetaria superando las barreras fronterizas y donde los Estados y las Economías nacionales pierden importancia como coordenadas clásicas de referencia, para dar paso a un sistema de economía mundial que tiende a homogeneizar las formas de organización de las empresas, los sistemas de producción y el comercio internacional (BERNAL-MEZA, 2000).

Más allá del simple reforzamiento de las relaciones económicas internacionales, el rasgo esencial que diferencia este proceso es la generalización progresiva de una lógica mundializada que orienta la activación de los agentes económicos respecto a líneas de producción, delimitación de mercados y localización de las actividades. De este modo, tanto la producción, como la circulación y la distribución son organizadas a escala mundial.

Con relación a los territorios, se genera una nueva Geografía Económica a partir de la redistribución espacial o la sustitución de actividades económicas, de acuerdo a las ventajas comparativas o competitivas que se presentan para la producción orientada hacia los mercados externos, impulsando procesos de modernización y especialización productiva. De este modo, la economía mundial emergente puede ser considerada como un mosaico de regiones productivas especializadas y fuertemente dependientes de los mercados mundiales (MÉNDEZ, 2003).

En este contexto, los espacios rurales adquieren un rol protagónico en la economía en función de sus respectivas ventajas comparativas, orientando la inversión y el em- 
pleo hacia las actividades primarias basadas en la explotación de los recursos naturales, generando una dinámica que rompe con lo planteado en la Teoría del Dualismo Estructural (LEWIS, 1954), que le asignaba al sector rural un rol subsidiario en la economía durante la etapa de Industrialización Sustitutiva, dando paso a una nueva concepción de lo rural explicitada en la Teoría del Dualismo Intra-rural o de fragmentación rural (SILI, 2002), que explica las diferencias observadas al interior de las áreas rurales con el surgimiento de nuevas actividades exportadoras, coexistiendo con la agricultura tradicional orientada a los mercados internos, generando una contradicción interna entre tradición y modernidad que responde a modelos productivos y culturales con lógicas de financiamiento distintos.

Pero el potencial rural va más allá de lo productivo basado en las actividades tradicionales de tipo silvoagropecuario, por cuanto hoy día su valorización es holística. "Se le valora como reserva de recursos naturales y paisajes; se le relaciona con el medio ambiente y la calidad de vida; se le visualiza como alternativa a la concentración urbana; se le valoriza en su vínculo con equilibrios regionales; se le considera universo de actividades multisectoriales y se opta por premiar a los asentamientos humanos, las industrias y las instituciones que alli se instalan"'(ECHEÑIQUE, 2001). Pero hay también un renacer de la conciencia territorial, después de décadas marcadas por la migración, el abandono del campo y la simple búsqueda de la modernización, y por ello, los territorios rurales en particular, tienen esa dimensión de pertenencia tal vez más fuerte que los otros. "Es el terruño que al transformarse violentamente y saturarse la vida urbana recomienza nuevamente a ser anhelado, recreado y valorado"(BENGOA, 2007).

El mundo rural cobra nuevos sentidos para una sociedad que adopta formas más flexibles en la localización de la residencia y de los procesos productivos. La agricultura tradicional comparte protagonismo con nuevas actividades consumidoras de espacio y con mayores perspectivas de desarrollo. Como resultado, el espacio rural adquiere la imagen de un "caleidoscopio"donde se conjuga la posibilidad de combinar múltiples usos y funciones con la oportunidad de llevar a cabo una ordenación de tales actividades. Si es válida la interrogante respecto a si el campo continuará despoblándose o por el contrario puede retener a parte de su población y aun atraer a migrantes de la ciudad, el uso residencial del espacio rural en el contexto de la Ordenación del Territorio es por tanto, una tarea pendiente (LEANDER, 2001).

Se constata en términos demográficos, que los territorios rurales modernizados están marcando una inflexión en las tendencias migratorias de la dinámica poblacional, incrementando gradualmente su número $\mathrm{ab}$ soluto por aporte de pobladores de origen urbano que toman la decisión de residir en el campo abandonando las ciudades centrales, lo cual se complementa además en algunas áreas con un crecimiento natural positivo. Esta tendencia, que en los países desarrollados se inicia en la década de los 70 , es la expresión de un cierto renacimiento rural que parece responder a algo más que cambios transitorios o coyunturales, sino a una revalorización del campo como "lugar para vivir en forma estable"(ROMERO \& FARINÓS, 2004).

Este fenómeno implica a su vez, cambios notables en la estructura social y en las funciones desarrolladas en el sector rural, donde la competencia por el uso del suelo no sólo se estaría manifestando entre las actividades primarias tradicionales y modernas, sino también entre el uso productivo y el uso residencial del suelo. Lo peculiar en el caso chileno, es que no sólo el fenómeno señalado se hace presente a partir de los ' 90 , sino que además, se detecta una retención de los pobladores rurales en sus áreas de origen a través de la construcción por parte del Estado de conjuntos de viviendas sociales -los villorrios agrícolas- coexistiendo con las denominadas "parcelas de agrado"y los condominios, ambos de construcción privada, 
operando las dos modalidades como "punta de lanza"para viabilizar la urbanización del campo (RIFFO \& RETAMALES, 2005).

Con respecto al uso residencial para pobladores de origen rural en Villorrios Agrícolas, una problemática específica que se presenta, es que en el contexto de la Globalización y Modernización productiva la modificación del modelo económico y especialmente de las políticas macroeconómicas para incentivar las exportaciones, valorizó las tierras con potencial productivo y dinamizó el mercado de suelos agrícolas, y ello explica la dificultad de los pobladores rurales pobres para encontrar tierras para uso residencial, lo cual tiende a reproducir la problemática existente al respecto en las áreas urbanas (LEANDER, 2001).

En las economías capitalistas, el suelo es considerado como una mercancía, aunque pueden existir ciertas restricciones con relación a su propiedad y utilización para salvaguardar el interés público. Por esa razón, su valor y en consecuencia los usos que se le asignan están regulados por los mecanismos de mercado, y por tanto, todo modelo de uso del suelo en un lugar y tiempo concretos, es el resultado de una competencia entre usos potenciales que operan sobre una situación heredada del pasado y desde esta perspectiva, los patrones de uso del suelo y los valores de éste serán siempre recíprocamente determinantes. En este sentido, si los precios del suelo condicionan el acceso de los pobres, el patrón de segregación y sus perspectivas de integración social, la localización periférica de los asentamientos rurales determina una gran escala de segregación y a su vez viajes más largos y caros, reduciendo con ello las perspectivas de contacto social de los pobladores (SABATINI, 2000).

Las transformaciones recientes que tienen como escenario las áreas rurales plantean nuevos problemas y nuevos desafíos, por cuanto el aprovechamiento de las ventajas comparativas efectivamente ha permitido la desconcentración espacial de la economía, movilizando inversiones hacia las regiones y especialmente hacia las áreas rurales donde se desarrollan las principales actividades económicas que tienen como destino los mercados externos. Pero la modernización y especialización productiva no es inocua en términos sociales, por cuanto el interés por invertir en el sector rural ha estimulado el mercado de la tierra generando procesos relacionados de descampesinización y concentración de la propiedad (RIFFO \& RETAMALES, 2007).

Surge entonces el problema de la retención espacial de los pobladores rurales sin tierra y sin casa, para evitar su desplazamiento hacia los centros urbanos donde pasarían a formar parte de los excluidos o marginados, dado sus bajos niveles de instrucción y calificación. Es en este contexto que interviene el Estado a través del Ministerio de Vivienda y Urbanismo (MINVU) y su Política de Subsidio Habitacional, con su proyecto de formación de Villas o Villorrios rurales, el que se ha desarrollado a lo largo de Chile, cambiando con ello el perfil tradicional del paisaje rural a partir de la construcción de estos conjuntos habitacionales de marcado sesgo urbano.

Los objetivos planteados por el MINVU al respecto, eran retener a la población rural en sus áreas de origen mejorando la calidad de vida de los pobladores beneficiados a partir del acceso a la vivienda propia y la urbanización del hábitat, ya que "así como se plantea la idea de hacer ciudad, debe estar también presente la idea de construir hábitat rural a través de la creación de Villorrios abordada en forma multidisciplinaria"(MINVU, 1994). Una nueva ruralidad que dignifique el espacio rural y a sus pobladores y contribuya a su radicación en forma sustentable reforzando su identidad y cultura. Cada proyecto de villorrio por lo tanto, debiera ser parte integrante de un programa, conjunto de inversiones o alternativas vigentes de desarrollo económico productivo, por cuanto "Agrupar a la población rural sin alternativas reales de trabajo constituiría una mala inversión pública, ya que los costos sociales que engendraría serían su- 
periores a las ventajas que se pretendería obtener"'(MINVU, 1994).

El MINVU define el Villorrio Rural como Asentamiento Humano separado de la ciudad o centro urbano, de una extensión inferior a 2.500 habitantes, con una o varias actividades productivas que aseguren fuentes laborales, dotado de infraestructura básica y social acorde con el desarrollo de ellas en el país. El problema es que los pobladores solo pueden acceder a un mercado secundario de tierras de menor valor comercial y situadas en áreas periféricas, lo que contribuye a una segregación socio-espacial de estos conjuntos dado el nivel de ingresos de sus habitantes, reduciendo con ello las condiciones objetivas de bienestar de la población.

Dentro de una línea de investigación CEPAL/ ECLAC (2003), que se orienta al problema de la pobreza rural en América Latina, su expresión según país y la caracterización del problema rural y nivel de desarrollo, se señala que aún no se ha evaluado en Chile el impacto de las políticas de mejoramiento de la habitabilidad de estas áreas, en particular mediante la creación de villorrios y su relación con la economía rural.

\section{Hábitat, Habitabilidad y Vulnerabilidad}

Si se define el hábitat como la forma en que el hombre ocupa y organiza el espacio y las actividades que se relacionan con éste, ello implica necesariamente la intervención del espacio físico y su modificación consecuente, derivando en patrones de poblamiento disperso o concentrado.

En las regiones inundables, los asentamientos se ubican en puntos altos, en los conos de deyección de los valles montañosos y en las lomas o colinas de los llanos de aluvión situados entre ríos, en tanto que en espacios homogéneos, como las llanuras o planicies, el emplazamiento del hábitat rural no se guía por las mismas reglas y otros factores se imponen al factor físico, generando un modelo concentrado de poblamiento.

En el pasado, la formación de núcleos poblados derivaba fundamentalmente de factores históricos, geográficos y políticos, pero en la actualidad el factor económico resulta ser el predominante, vinculado al valor del suelo en áreas rurales. Históricamente, el hábitat disperso fue la forma original del poblamiento rural, el cual se relaciona con la disponibilidad, dimensiones y formas de explotación de las áreas rurales, en tanto los caseríos y aldeas cumplían con su función de proveer de servicios a su entorno.

De acuerdo a los postulados del Ministerio de Vivienda y Urbanismo implícitos en la modificación de la normativa del Programa de Subsidio Habitacional Rural (Título II), lo que se espera es construir un nuevo Hábitat Rural a partir de la formación de nuevos asentamientos poblados -Villorrios o villas- que dignifique la calidad de vida de sus habitantes facilitándoles no solo el acceso a la vivienda propia, sino también a los servicios básicos y el equipamiento comunitario, reteniendo a los pobladores rurales en sus áreas de origen y preservando sus redes de apoyo familiar y social. Se trata entonces de construir hábitat rural considerando simultáneamente las condiciones del espacio físico, del espacio construido y del espacio social.

La concentración de la población rural en núcleos poblados permite reducir los costos de la urbanización y el aislamiento social, pero este proceso implica reducir el espacio rural para fines productivos, con lo cual éste se valoriza aún más en un contexto de modernización y por lo tanto, este proceso debiera estar incorporado en una política de asentamientos humanos.

De acuerdo a la Conferencia de las Naciones Unidas Hábitat II (Estambul, 1996), una Política de Asentamientos Humanos debiera considerar los siguientes objetivos: 
- Propiciar un poblamiento más equilibrado del territorio que oriente un mejoramiento efectivo de las condiciones de vida de la población, superando el problema de la pobreza.

- Programar un Ordenamiento Territorial Sustentable, que considere al mismo tiempo la productividad y el crecimiento económico, la equidad social con una mejor distribución de los beneficios obtenidos y la preservación de los recursos sobre los que se sustenta el crecimiento.

- Lograr el financiamiento adecuado de los asentamientos humanos, a través de la participación compartida del sector público, del sector privado y de la población comprometida.

- Propiciar la descentralización de las políticas y gestión de los asentamientos humanos, fortaleciendo el rol de los gobiernos regionales y locales, así como la participación de la población local a través de formas como la organización y el ahorro.

- Insertar la Política sobre Asentamientos humanos en el contexto de un Proyecto Global de Desarrollo regional y nacional, a objeto de potenciar programas integrados de acción territorial socialmente focalizados.

El cumplimiento de estos objetivos en el sector rural implica por una parte, optimizar la localización espacial de los nuevos asentamientos poblados para reducir los riesgos ambientales y propiciar la preservación de las tierras de aptitud agrícola en el marco de una Política de Ordenamiento Territorial y por otra parte, mejorar los estándares constructivos en términos de superficie, calidad y diseño de las viviendas rurales, considerando las condiciones ecológicas de los lugares de emplazamiento y los modos de vida de los pobladores.

Por su parte, el mejoramiento de la calidad de vida de la población rural implica opti- mizar las condiciones de habitabilidad de los asentamientos poblados.

En Arquitectura, el concepto de habitabilidad alude preferentemente a las características del espacio construido y específicamente de las viviendas, a efecto de reducir la vulnerabilidad estructural de las edificaciones para proporcionar los requisitos mínimos de cobijo frente al medio.

El MINVU, a través de la Ordenanza General, entiende la habitabilidad en relación a las condiciones de un recinto que lo pueden hacer habitable o no (ventilación, iluminación, acústica, acondicionamiento térmico, saneamiento, privacidad y accesibilidad) y su condición necesaria de acuerdo al uso (DIPUC, 2008).

De esta manera, la conformación de la habitabilidad atañe a la organización física y condiciones aptas para que un espacio sea habitable, donde la habitabilidad es considerada como la totalidad de la estructura espacial de los conjuntos residenciales utilizando la materialidad arquitectónica.

Por su parte, COLAVIDAS \& SALAS (2005) acuñan el concepto de Habitabilidad básica para referirse al conjunto de estructuras físicas elementales (viviendas, cobijos, espacios públicos, infraestructura social, servicios comunitarios), que tanto en su referente social como económico satisfacen las necesidades básicas de residencia mínima admisible.

Según la Organización Mundial de la Salud (OMS), el concepto de vivienda saludable abarca la prestación funcional y el adecuado desarrollo físico, social y mental de las condiciones de salud, seguridad, higiene, comodidad y privacidad". La importancia de estos conceptos radica en que amplían el ámbito de la evaluación de la calidad de la vivienda, que hoy está restringida a la idea de confort, aunque en Chile se carece de parámetros reconocidos para implementar y 
evaluar las condiciones adecuadas de habitabilidad en la vivienda (INVI, 2004).

En Geografía por su parte, el concepto de habitabilidad trasciende la escala de la vivienda y del conjunto residencial para referirse fundamentalmente a las características físico-ambientales del espacio en que éstos se emplazan, para de allí determinar las condiciones de vulnerabilidad frente al riesgo de catástrofes derivadas de eventos naturales.

La vulnerabilidad a su vez, se puede expresar no sólo en términos físicos -por la ubicación de los asentamientos en áreas de riesgo- sino también como vulnerabilidad ecológica -por intervención humana sobre el medio físico-, alterando el funcionamiento de los ecosistemas.

La problemática de la habitabilidad física y ecológica deriva a su vez de la ocupación creciente de las áreas de riesgo con fines residenciales, lo cual se acentúa en países en desarrollo, donde la escasez de suelos para estos fines y/o la falta de acceso a estos por parte de la población de menores recursos es el factor recurrente, lo que se exacerba por el crecimiento demográfico.

La ocupación de áreas de riesgo a su vez, no solo responde a asentamientos de tipo informal, sino que el propio Estado al desarrollar programas habitacionales para la población carente, ha desconsiderado las características del medio natural de su emplazamiento, lo cual se ve acentuado por la percepción del riesgo de quienes habitan en dichas áreas, los que tienden a subestimar el riesgo por una parte y a sobreestimar las defensas derivadas de las obras de arte construidas por las autoridades para tal efecto, por otra (BOSQUE, 1976).

Los desastres en un sentido amplio, son resultados de eventos o procesos de connotación negativa para la población, cuando las áreas de riesgo de este tipo de fenómenos son ocupadas sin considerar sus efectos. Cuando ellos ocurren en áreas no ocupadas no dejan de ser más que fenómenos de la naturaleza dentro de la dinámica que le es propia, para transformarse en catástrofes o desastres por la acción antrópica que ignora dicha dinámica. En este sentido, se avanza hacia la sustentabilidad ambiental de los asentamientos cuando se incorporan las amenazas dentro de la planificación, puesto que nada de lo que haga el hombre sobre el espacio es ajeno a la naturaleza (FERRANDO, 2003).

En efecto, los desastres o catástrofes son naturales en sentido estricto respecto a su origen en la naturaleza (terremotos, tsunamis, erupciones volcánicas, sequías, huracanes, inundaciones), pero respecto a sus efectos, puede señalarse que estos son derivados de la acción antrópica y son por tanto desastres sociales y/o económicos. Así, una inundación constituye un fenómeno natural, normal y esperable, pues forma parte del comportamiento hidrometeorológico de una localidad o región, que alcanza la categoría de desastre cuando impacta en un grupo humano con consecuencias sociales y económicas. La vulnerabilidad social es por tanto, el elemento que define la magnitud del desastre (HERZER \& DI VIRGILIO, 1996).

Los riesgos naturales por tanto, son eventos extremos de la naturaleza, que se constituyen en catástrofes cuando afectan la vida y la propiedad de la población que reside en dichas áreas y cuya gravedad depende de la intensidad del evento natural y de la acción modificadora del medio por parte de la población, de manera que en términos de prevención, la alta incidencia que tiene el factor humano en la generación de este tipo de eventos hace posible adoptar acciones tendientes a evitar las catástrofes, las cuales pueden ser de tipo estructural -proyectos de ingeniería- o no estructurales, como es la implementación de sistemas de alarma (LARRAÍN, 1994).

Los desastres o catástrofes afectan en mayor medida a los sectores más pobres de la sociedad, debido a su condición de vulnera- 
bilidad física (ocupación de áreas de riesgo) o vulnerabilidad técnica (precariedad de la vivienda), y en este sentido, la eventualidad de ocurrencia de un fenómeno de la naturaleza constituye una amenaza, la que se configura en una situación de riesgo para la población en relación con el nivel de vulnerabilidad que presenta el área ocupada, de cuya correspondencia resultará o no una situación de desastre; por ello, en términos de prevención se actúa sobre la vulnerabilidad más que sobre la amenaza, puesto que estos fenómenos de la naturaleza son inevitables (FERRANDO, 2003).

Un desastre, por tanto, hace referencia a una combinación de factores naturales y humanos; no se trata de un acontecimiento físico sino de un proceso social, económico y político desencadenado por un fenómeno natural.

\section{ANTECEDENTES GENERALES}

\section{Normativa legal relacionada con la con- formación de Villorrios Rurales en Chile}

En ausencia de un cuerpo legal específico sobre Ordenamiento Territorial de áreas rurales en Chile, operan los siguientes Instrumentos e Instituciones:

El Decreto Ley N ${ }^{\circ} 167$ de 1986 (MINVU) que reglamenta el Programa de Subsidio Habitacional Rural.

El Artículo 55 de la Ley General de Urbanismo y Construcciones (MINVU) que reglamenta el Uso de Suelo.

La Comisión Mixta de Uso del Suelo que reglamenta el Cambio de Uso del Suelo Rural.

Programa de Subsidio Habitacional Rural (D.L. 167 de agosto 1986): Reglamento

El reglamento regula un sistema especial de Subsidio Habitacional destinado a facilitar el acceso de familias rurales de bajos ingresos a viviendas rurales definitivas, seguras e higiénicas, nuevas y terminadas, cuya finalidad sea la habitación permanente. Se entiende como vivienda nueva, aquella que desde su construcción no ha sido habitada ni destinada a ningún otro uso (Artículo $1^{\circ}$ ).

El Subsidio habitacional rural es una ayuda estatal directa, que se otorga por una sola vez al beneficiario sin cargo de restitución por parte de éste, y que constituye un complemento de su ahorro (Artículo $2^{\circ}$ ).

Se entenderá por vivienda rural aquella emplazada en cualquier lugar del territorio nacional, excluidas las áreas urbanas de las localidades de más de 2.500 habitantes (según el último Censo de Población anterior a la fecha del respectivo llamado a postulación) y las áreas de expansión urbana. Excepcionalmente, por resoluciones del Ministerio de Vivienda y Urbanismo, dictadas a requerimiento de la Secretaría Ministerial respectiva, podrá autorizarse la aplicación de este Subsidio a viviendas emplazadas en áreas antes excluidas (Artículo $3^{\circ}$ ).

Para los efectos de postular al Subsidio habitacional rural, se deberá acreditar derechos sobre un terreno ubicado en las áreas en que pueda aplicarse el Subsidio, sea éste un sitio de carácter habitacional o bien un predio explotable que no exceda del equivalente a 12 hás. de riego básico (Artículo $9^{\circ}$ ).

Podrán postular en forma colectiva al subsidio a que se refiere este Reglamento, los socios de cooperativas de vivienda y las personas naturales constituidas en comunidades, siempre que presenten un anteproyecto de la subdivisión o loteo correspondiente al conjunto habitacional que desarrollarán, que podrá corresponder a una aldea minera, villorrio agrícola, caleta pesquera, u otra población. Dicho anteproyecto deberá cumplir con el siguiente requisito y con los que se señalen por resoluciones del Ministerio de Vivienda y Urbanismo (MINVU): Tratándose de conjuntos destinados a ser emplazados fuera de los límites urbanos o de expansión urbana, deben contar con la autorización en principio de la respectiva Secre- 
taría de Agricultura, para cambio de uso de suelo, y estar aprobados en principio por la Secretaría Ministerial de Vivienda y Urbanismo correspondiente (Artículo $17 \mathrm{~A}$ ).

El Certificado de Subsidio de los socios de cooperativas de vivienda y de los miembros de comunidades que postulan colectivamente se otorgarán y se pagarán individualmente a cada uno de los socios o comuneros beneficiarios, de acuerdo a las normas generales (Artículo 21).

\section{Modificación del Sistema de Subsidio Habitacional Rural (D.S. $N^{\circ} 117$ de 2002)}

Señala que se trata de un sistema habitacional de cobertura nacional dirigido a atender a familias de escasos recursos del sector rural, vinculadas a las diferentes actividades productivas (campesinos, pescadores, pirquineros, agricultores, trabajadores forestales o temporeros), a través de un subsidio estatal que contribuye a financiar la construcción o adquisición de una vivienda rural o el mejoramiento de la vivienda rural existente. El Programa consta de tres modalidades de atención, reguladas por un título preliminar (I, II y III).

\section{Título II: De la Postulación colectiva a Subsidio para la formación de nuevos Villorrios}

Está dirigido a familias de escasos recursos que aplicarán el beneficio en localidades del sector rural interesadas en conformar nuevos villorrios (30 integrantes como mínimo) o adosar proyectos habitacionales a proyectos existentes (mínimo 10 integrantes).

El Subsidio alcanza a las 220 UF, salvo excepciones en comunas especiales (300 UF). Como requisito de postulación, se requiere disponer de un terreno apto para la construcción de la vivienda, que tratándose de un terreno explotable no puede exceder las 8 hás. de riego básico; certificación de entidad financiera de un ahorro previo de 10 UF; pre- sentación de proyecto habitacional con acreditación de dominio o tenencia de terreno, proyecto de loteo con aprobación municipal, acreditación de factibilidad de servicios, cambio de uso de suelo y presupuesto.

Ya a partir de 1994, el MINVU especificaba que a través de la postulación colectiva al Subsidio habitacional rural se estimularía la formación de villas o villorrios rurales, ya que para urbanizar el campo es clave que existan pequeños agrupamientos rurales, por cuanto es muy difícil llegar con soluciones individuales a una población dispersa. La propuesta es "radicar y no erradicar a la población rural, ya que las familias rurales tienen derecho a elegir dónde quieren vivir de acuerdo a sus expectativas laborales, a sus condiciones socioculturales y a sus necesidades familiares. En este sentido, dar calidad de vida rural significa infraestructura básica, existencia de caminos, pavimentos a la puerta de la casa, no sufrir anegamientos ni inundaciones y disponer de servicios básicos, y se ha estado dando una señal equívoca de que sólo en la ciudad es posible encontrar tales beneficios "(Edmundo Hermosilla, Ministro de Vivienda y Urbanismo, 1994).

\section{Ley General de Urbanismo y Construc- ciones: Artículo 55}

Señala que el espacio rural es el espacio con el cual el área urbana mantiene una fuerte interdependencia en términos funcionales y económicos, especialmente en comunas cuya actividad predominante está ligada a recursos naturales y en aquellas constituidas por un conjunto de núcleos urbanos separados entre sí (hinterland asociado a cada centro poblado).

Fuera de los límites urbanos establecidos en los Planes Reguladores, no será permitido abrir calles, subdividir para formar poblaciones ni levantar construcciones, salvo aquellas que fueran necesarias para la explotación agrícola o para viviendas del 
propietario y de sus trabajadores, o para la construcción de conjuntos habitacionales de viviendas sociales o de viviendas hasta un valor de 1.000 UF que cuenten con los requisitos para obtener el subsidio del Estado.

Corresponde a la Secretaría Regional Ministerial (SEREMI) de Vivienda respectiva, controlar que las subdivisiones y construcciones en terrenos rurales con fines ajenos a la agricultura no originen nuevos núcleos urbanos al margen de la planificación urbano-regional. Con dicho objetivo, cuando sea necesario urbanizar terrenos rurales para complementar alguna actividad industrial con viviendas, dotar de equipamiento a algún sector rural o habilitar un balneario, un campamento turístico, o para la construcción de un conjunto de viviendas sociales o de viviendas hasta un valor de $1.000 \mathrm{UF}$, la autorización que otorgue la SEREMI de Agricultura requerirá del informe previo favorable de la SEREMI de Vivienda que señalará el grado mínimo de urbanización que deberá tener esa división predial, conforme a lo que establezca la Ordenanza General de Urbanismo y Construcciones.

Esta Ordenanza en su Artículo 6.3.3. establece las condiciones mínimas de urbanización de conjuntos de viviendas en el área rural, señalando que dichas disposiciones constituyen normas de excepción, y por lo tanto, deberán ser aplicadas de acuerdo a los criterios fijados por las respectivas Secretarías Regionales.

\section{Reglamento del Cambio de Uso de Suelo Rural para la conformación de Villorrios Rurales}

El Artículo 55 de la Ley General de Urbanismo y Construcciones, señala que la Secretaría Regional de Vivienda y Urbanismo es el organismo responsable de cautelar que las subdivisiones y construcciones en terrenos rurales, con fines ajenos a la agricultura, no originen nuevos núcleos urbanos al margen de la planificación urbano-regional (Inciso 2).

El mismo Artículo 55, establece que dichas construcciones deberán ser aprobadas por la Dirección de Obras Municipales respectiva, previo informe favorable de la SEREMI de Vivienda y del SAG (Servicio Agrícola Ganadero), ambos organismos integrados en la actualidad en el Comité Mixto que interviene en la autorización del cambio de uso de suelo rural.

En particular, el permiso para subdividir y urbanizar terrenos rurales para viviendas y/o actividades industriales, es un permiso ambiental sectorial $\left(N^{\circ}\right.$ 97) relacionado con el Artículo 55 de la Ley General de Urbanismo y Construcciones. Atendiendo a este artículo, deben incorporarse dentro de una Evaluación Ambiental todos aquellos elementos necesarios para acreditar que no se originen efectos no deseables respecto a la planificación urbano-regional y que puedan generar nuevos núcleos urbanos al margen de la planificación territorial.

En consecuencia, la información que debe aportar el proponente de una subdivisión o construcción en áreas rurales, debe tener relación con todos y cada uno de los aspectos que son usualmente tratados por los Instrumentos de planificación vigentes, esto es: factibilidad de agua potable, electricidad y alcantarillado, ausencia de riesgos de todo tipo (naturales o antrópicos), vialidad, densidad, accesibilidad, protección del patrimonio cultural, del paisaje y de los recursos naturales renovables y no renovables, señalándose expresamente la protección mayoritaria de los suelos cultivables interpuesto por el Ministerio de Agricultura, respecto a la no-ocupación de los suelos de aptitud agrícola (TASVILLE, et al. 2002).

La autorización del cambio de uso del suelo solicitado, es a su vez, uno de los principales requisitos para postular al Subsidio Rural. 


\section{RESULTADOS}

El análisis de la localización espacial de estos asentamientos en relación al medio físico circundante, da cuenta de las condiciones de habitabilidad de los sitios en que se emplazan los villorrios.

La Ley 19.525, que regula el sistema de evacuación y drenaje de aguas lluvias, establece que es obligatorio para las ciudades o centros poblados de más de 50.000 habitantes contar con un Plan Maestro que defina las redes primarias de evacuación y drenaje de aguas lluvias. Dado que los villorrios agrícolas son núcleos poblados con una población muy inferior a la mencionada, se encuentran al margen de esta legislación y el escurrimiento se efectúa a través de sus calles y sistema hídrico, razón por la cual conocer la distribución espacial de la red hídrica en las comunas y la localización que tienen los villorrios con respecto a ésta, resulta de vital importancia.

A su vez, la topografía, que se manifiesta en la pendiente del terreno en que estos asentamientos se emplazan, muchas veces constituye un factor que incide en el escurrimiento de las aguas superficiales, y además, una seria limitante para el desarrollo e implementación de la infraestructura necesaria en estos asentamientos, de aquí entonces la importancia de considerar este aspecto dentro del análisis.

Por otra parte, la normativa vigente que regula la formación de villorrios establece que estos asentamientos no deben localizarse en terrenos que presenten aptitud agrícola, por lo tanto, la consideración de este aspecto es clave para dar cuenta del cumplimiento de esta normativa.

\section{Comuna de Curicó}

Como se observa en el mapa $\mathrm{N}^{\circ} 1$, la Red hídrica de la comuna de Curicó está dominada por la presencia de dos cauces principales que corresponden a los ríos Teno y Lontué. El primero de ellos constituye el límite norte con las comunas de Teno y Rauco y el segundo marca su presencia constituyéndose en el límite occidental con la comuna de Molina. $\mathrm{Al}$ interior de la comuna y en directa relación con la localización espacial de los villorrios, cobran importancia las subcuencas del estero Quetequete, del estero Chequenlemu y la del estero Potrero Grande.

Respecto a la vulnerabilidad de los villorrios a los riesgos de inundación derivados de estos cursos de agua, el sector norte de la comuna en términos hidrológicos está dominado por la presencia del río Teno, que con sus desbordes de primavera e invierno afecta a los villorrios Vista Hermosa, Villa Macondo, Los Guindos, San Vicente y Santa Filomena, hecho que se corrobora con el resultado de las entrevistas aplicadas en estos asentamientos, en donde los dirigentes manifestaron verse afectados por las inundaciones de este río.

En el sector Nor-occidental de la comuna, nace del río Teno la subcuenca del estero Quetequete (que se desplaza en sentido $\mathrm{N}-\mathrm{S}$ ), en cuyas cercanías se localizan los villorrios El Membrillo y Santa Carmen, siendo este último seriamente afectado por las crecidas de este estero que dejan inhabilitados los caminos que conectan a este asentamiento con el resto de la comuna.

Al sur de la ciudad de Curicó y en las proximidades del estero Chequenlemu (que escurre en sentido W-E) se ubican los villorrios Julián Lozano, Progreso 1 y Progreso 2, que podrían verse afectados por eventos de inundaciones o desbordes de este cauce. La información obtenida de la entrevista corrobora esta situación en los villorrios Progreso 1 y 2 , sin embargo y pese a la cercanía del villorrio Julián Lozano, los pobladores de este asentamiento no manifestaron tener este tipo de problemas. 
En el sector oriental de la comuna, y en las cercanías del estero Potrero Grande, afluente del río Lontué, se ubican los Villorrios Nuevo Amanecer, Villa Cordillera, Santa Marta y Villa Primavera, los cuales, dada su proximidad con este cauce podrían verse afectados por algún tipo de evento relacionado a las inundaciones o crecidas de este estero. Sin embargo y de acuerdo a los resultados de la entrevista, en solo dos de ellos, que corresponden a Villa Primavera y Nuevo Amanecer, esta situación representa un problema para los pobladores.
Las inundaciones de los villorrios, que muchas veces hacen llegar el agua hasta la puerta de las casas y dejan los caminos en muy malas condiciones, dificultando el acceso a estos asentamientos y la movilidad de los pobladores, acarrean además otros problemas de igual importancia, como son el arrastre de materiales, basuras y roedores, incrementando plagas y potenciales enfermedades y poniendo en riesgo los cultivos y la salud de los pobladores (ARMISÉN, 2004).

Mapa $N^{\circ} 1$. Localización de los villorrios de Curicó en relación a la Red Hídrica.

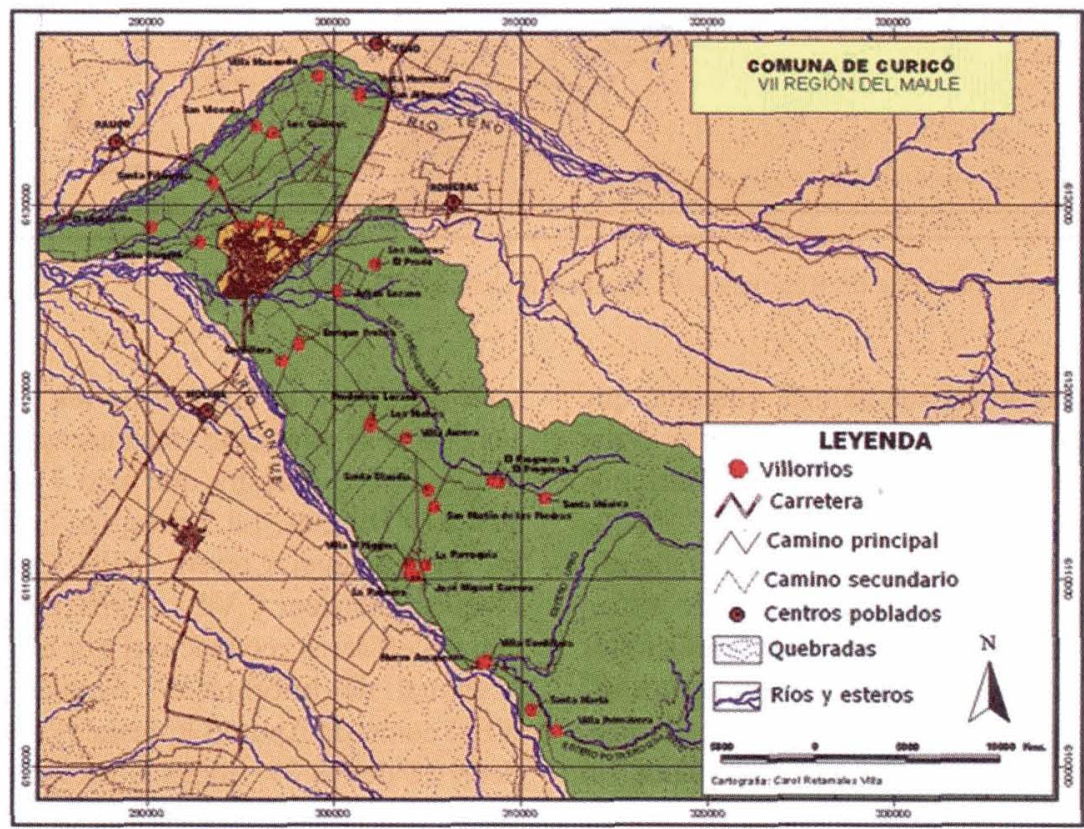

Fuente: Elaboración Retamales, C. Base Cartográfica IGM.

En relación a la localización de los villorrios con respecto a la pendiente, el mapa $\mathrm{N}^{\circ} 2$ muestra que en esta comuna 26 de los 29 villorrios están emplazados en terrenos con rango de pendiente de 0 al 3\%, lo que de acuerdo a la clasificación del State Survey of
Kansas (MOPT, 1993), que se muestra en la tabla $\mathrm{N}^{\circ} 1$, los sitúa en terrenos aptos para el desarrollo de distintos usos urbanos, dentro de los cuales se incluye el uso residencial y la infraestructura asociada. 
Mapa $\mathbf{N}^{\circ}$ 2. Localización de los villorrios de Curicó con respecto a las Pendientes.

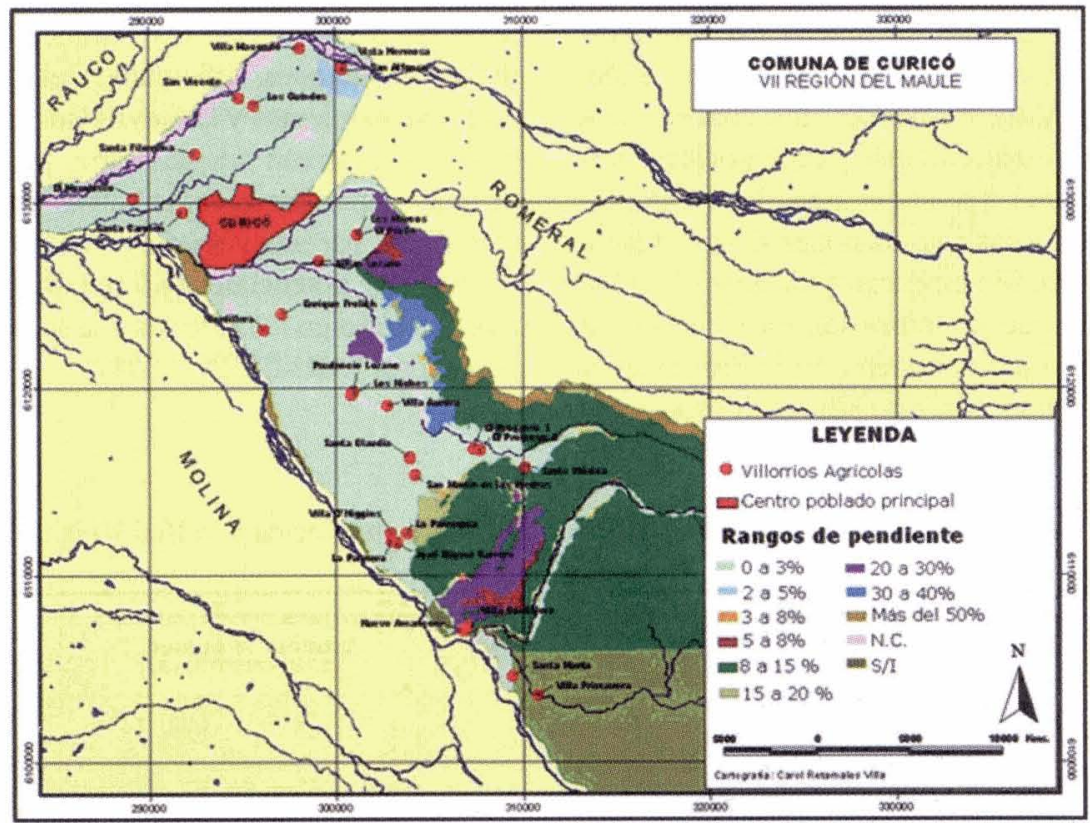

Fuente: Elaboración Retamales, C. En base a Cartografía IGM.

Dos de los Villorrios de esta comuna, que corresponden a Nuevo Amanecer y Villa Cordillera, están emplazados en terrenos con rangos de pendiente entre 8 y $15 \%$; de acuerdo a la clasificación mencionada anteriormente, el terreno en el que se sitúan estos asentamientos presenta limitaciones para la construcción de Infraestructura urbana. Lógicamente, estas restricciones presuponen que el uso del terreno se hace sin modificación de las pendientes; sin embargo, mediante recursos técnicos y aumentando las inversiones sería posible modificar las pendientes y desarrollar las actividades para las cuales existen limitaciones.
Con respecto a la aptitud de los suelos en los cuales se emplazan estos asentamientos, el mapa $\mathrm{N}^{\circ} 3$ muestra que solo 7 villorrios (Villa O'Higgins, La Parroquia, La Palmera, José Miguel Carrera, Villa Cordillera, Nuevo Amanecer y Villa Primavera), se localizan en áreas reconocidas por el Sistema Nacional de Información Ambiental (SINIA) como de Aptitud Forestal. El resto, es decir 22 de los 29 villorrios presentes en la comuna de Curicó, se localizan en áreas que el SINIA reconoce como de uso potencial agrícola, hecho que da cuenta de una falta a la normativa vigente que regula la conformación de villorrios y que establece que este tipo de asentamiento no debe localizarse en terrenos con potencial agrícola, a objeto de preservar estos suelos para esta actividad. 


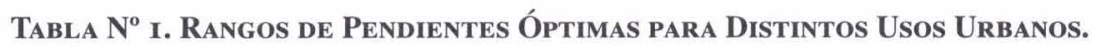

\begin{tabular}{|c|c|c|c|c|c|}
\hline \multirow{2}{*}{ Uso } & \multicolumn{5}{|c|}{ Rangos de Pendientes en $\%$} \\
\hline & $0-3$ & $3-5$ & $5-10$ & $10-15$ & más de 15 \\
\hline Áreas de Recreo & $x$ & $x$ & $x$ & $x$ & Sin límite \\
\hline Estructuras Urbanas & $x$ & $x$ & $x$ & $x$ & \\
\hline Usos Urbanos Generales & $x$ & $x$ & $x$ & $x$ & \\
\hline Carreteras & $x$ & $x$ & $x$ & & \\
\hline Sistema de Alcantarillado & $x$ & $x$ & & & \\
\hline Urbanizaciones Convencionales & $\mathrm{x}$ & & & $x$ & \\
\hline Autopistas & $x$ & $x$ & & & \\
\hline Aeropuertos & $x$ & & & & \\
\hline Ferrocarril & $x$ & & & & \\
\hline Operaciones con Maquinaria & \multirow{2}{*}{$x$} & \multirow{2}{*}{$x$} & \multirow{2}{*}{$\mathrm{x}$} & \multirow{2}{*}{$x$} & \multirow{2}{*}{$\begin{array}{c}\text { Hasta } \\
54 \%\end{array}$} \\
\hline y Vehículos Pesados & & & & & \\
\hline
\end{tabular}

Fuente: Guía para la Elaboración de Estudios del Medio Físico (MOPT). España, 1993.

Mapa No 3. Localización de los Villorrios de Curicó, con respecto al Uso Potencial del Suelo.

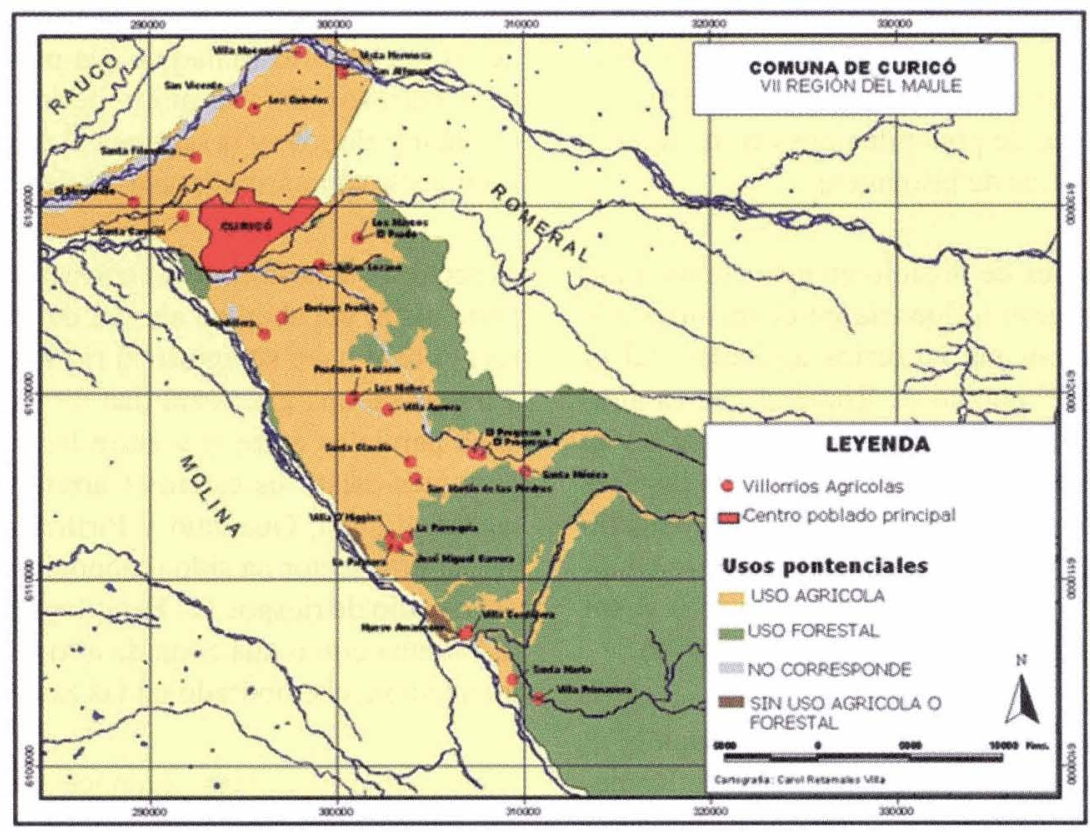

Fuente: Elaboración Retamales, C. En base a información SINIA. 


\section{Comuna de Romeral}

La comuna de Romeral en materia hidrológica y en estricta relación con la localización de los villorrios agrícolas, está dominada por la presencia del río Teno (que escurre en sentido SW-NE y se constituye en el límite natural que separa a Romeral de la comuna de Teno), y por la subcuenca del Estero Guaiquillo (dirección W-E).

El río Teno atraviesa en esta comuna un sector de baja pendiente y adquiere una forma anastomosada, lo que implica una alta carga de sedimentos y por lo tanto existe un riesgo de desborde durante las crecidas (WIEDERHOLD, 2004).

El estero Guaiquillo en tanto, recibe el aporte de aguas del cordón montañoso que separa a Romeral de la comuna de Curicó; este estero en su trayecto pasa cerca de los villorrios Luxemburgo, El Ángel y La Araucana y en su recorrido se acerca en forma paralela a algunos canales de regadío, provocando que los sectores adyacentes y entre estos cursos se vean fuertemente afectados en caso de inundaciones inducidas por el aumento de precipitaciones en invierno y los deshielos de primavera.

Los canales de regadío en esta comuna tienen una gran influencia en el sector donde se localizan los villorrios agrícolas; tal es el caso del pueblo de Romeral que es atravesado por un canal de regadío que en su trayecto también cruza el sector de las Tres Esquinas, en donde se localiza el villorrio Luxemburgo. Por su parte, el villorrio Guaico I se encuentra limitado al norte y al sur por canales de regadío (Ver mapa $\mathrm{N}^{\circ} 4$ ).

Con respecto a la pendiente, el mapa $\mathrm{N}^{\circ} 5$ muestra que los cuatro villorrios de Romeral están emplazados en rangos de pendiente de 0 y $3 \%$, lo que según la clasificación del State Survey of Kansas que se muestra en la tabla $\mathrm{N}^{\circ} 1$, los sitúa en terrenos aptos para el desarrollo de todas las actividades urbanas y la infraestructura asociada.

En cuanto a la localización de los villorrios de Romeral con respecto al uso potencial del suelo, el mapa $\mathrm{N}^{\circ} 6^{\circ}$ muestra que pese a que la normativa vigente establece que este tipo de asentamientos no deben situarse en terrenos de aptitud agrícola, todos los villorrios de esta comuna están emplazados en lo que el Sistema Nacional de Información Ambiental (SINIA) clasifica como suelos de aptitud agrícola.

\section{Comuna de Sagrada Familia}

En materia hidrológica, Sagrada Familia está dominada por el río Mataquito, que escurre en sentido W-E y nace de la unión de los ríos Teno y Lontué. El río Mataquito corresponde a un río excavado por antecedencia sobre las unidades geológicas de la Cordillera de la Costa, que atraviesa un amplio valle de sedimentación al cual debe su forma anastomosada. Dentro de la comuna existen dos sub cuencas que drenan sus aguas hacia el río Mataquito, la primera de ellas corresponde a la unión de los esteros Culenar y Belloto y la segunda al estero San Juan y sus tributarios (mapa $\mathrm{N}^{\circ} 7$ ).

El sector Este de la comuna corresponde a la parte distal del abanico aluvial del río Lontué, el cual hace su aporte al río Mataquito a través de una gran cantidad de cursos de agua paralelos entre sí y entre los más importantes están los esteros Carretones, $\mathrm{Pa}$ tagual, Piduco, Gualemo y Pirihuín. Justamente este sector ha sido reconocido dentro del estudio de riesgos del Plan Regulador de la comuna como una zona de alto riesgo de inundación, corroborado en las Entrevistas.

Dicho estudio además reconoce como zonas de muy alto riesgo de inundación a los cauces principales de los ríos Lontué y Mataquito, a la llanura de inundación de los mismos, definida por los terrenos que se encuentran entre el cauce principal del río 
Lontué y la localidad de Lo Valdivia y los cauces secundarios correspondientes a los esteros Carretones, Piduco, Patagual, Gualemo, Pirihuín y río Seco ya mencionados. Las terrazas fluviales inferiores presentan alto riesgo de inundación, ya que se encuentran limitando a los cauces principales y a la llanura de inundación, y en caso de ocurrir un evento extraordinario podrían cubrirse de agua. En la comuna de Sagrada Familia, esta unidad se encuentra en el sector comprendido entre Santa Elena hasta Santa Emilia. Las terrazas fluviales superiores presentan moderado peligro de inundación, ya que se encuentran en un nivel más elevado topográficamente y de inundarse sería en forma temporal por intensas lluvias en el momento en que escurren las aguas a zonas topográficas menos elevadas (PRC, anexo Factibilidad Sanitaria y Análisis de Aguas Lluvias de la Comuna de Sagrada Familia).

\section{$\operatorname{Mapa} \mathbf{N}^{\circ} 4$}

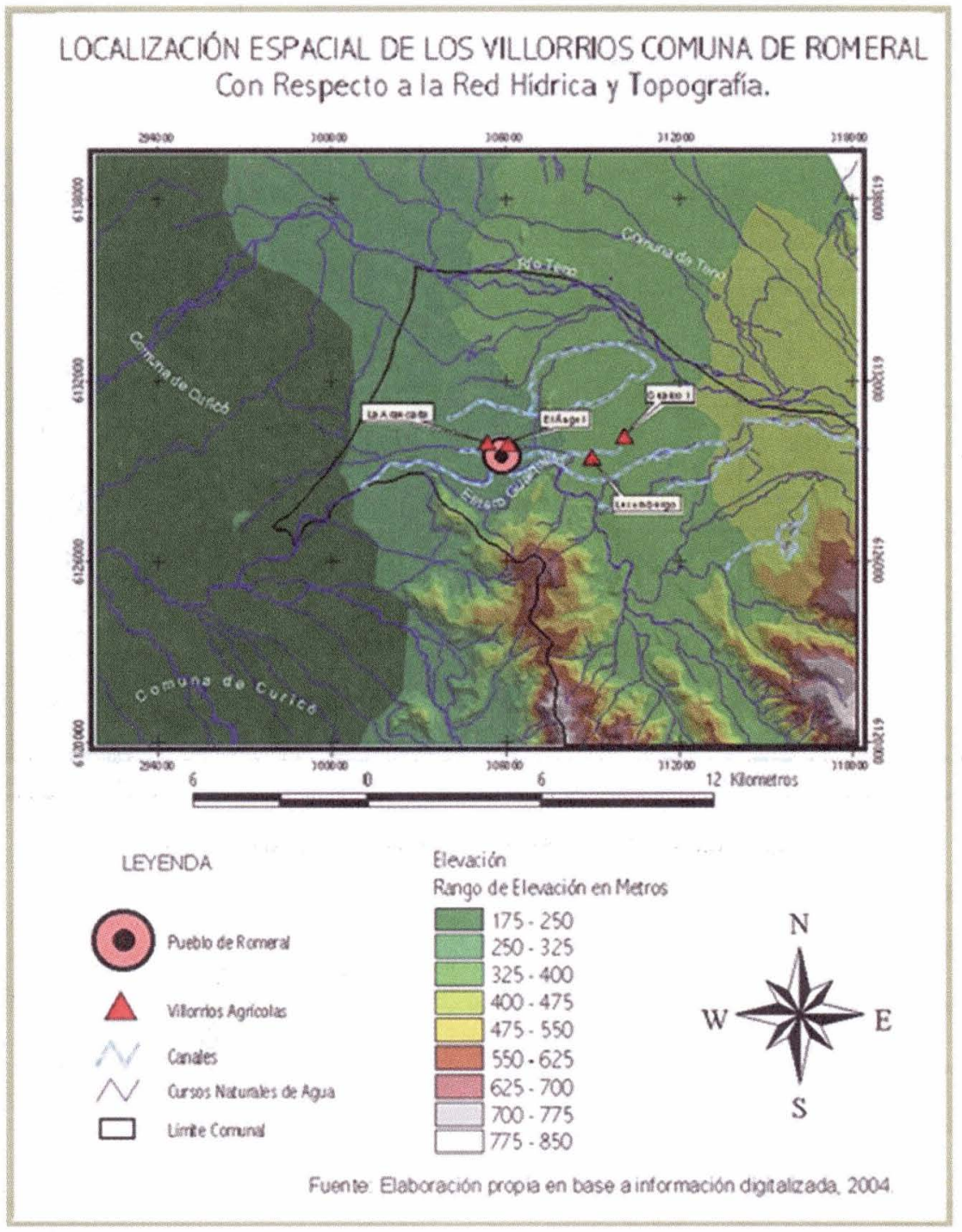

Fuente: Elaboración Wiederhold, E. en base a cartografía IGM. 
Mapa $\mathrm{N}^{\circ}$ 5. Localización de los Villorrios de Romeral con respecto a las Pendientes.

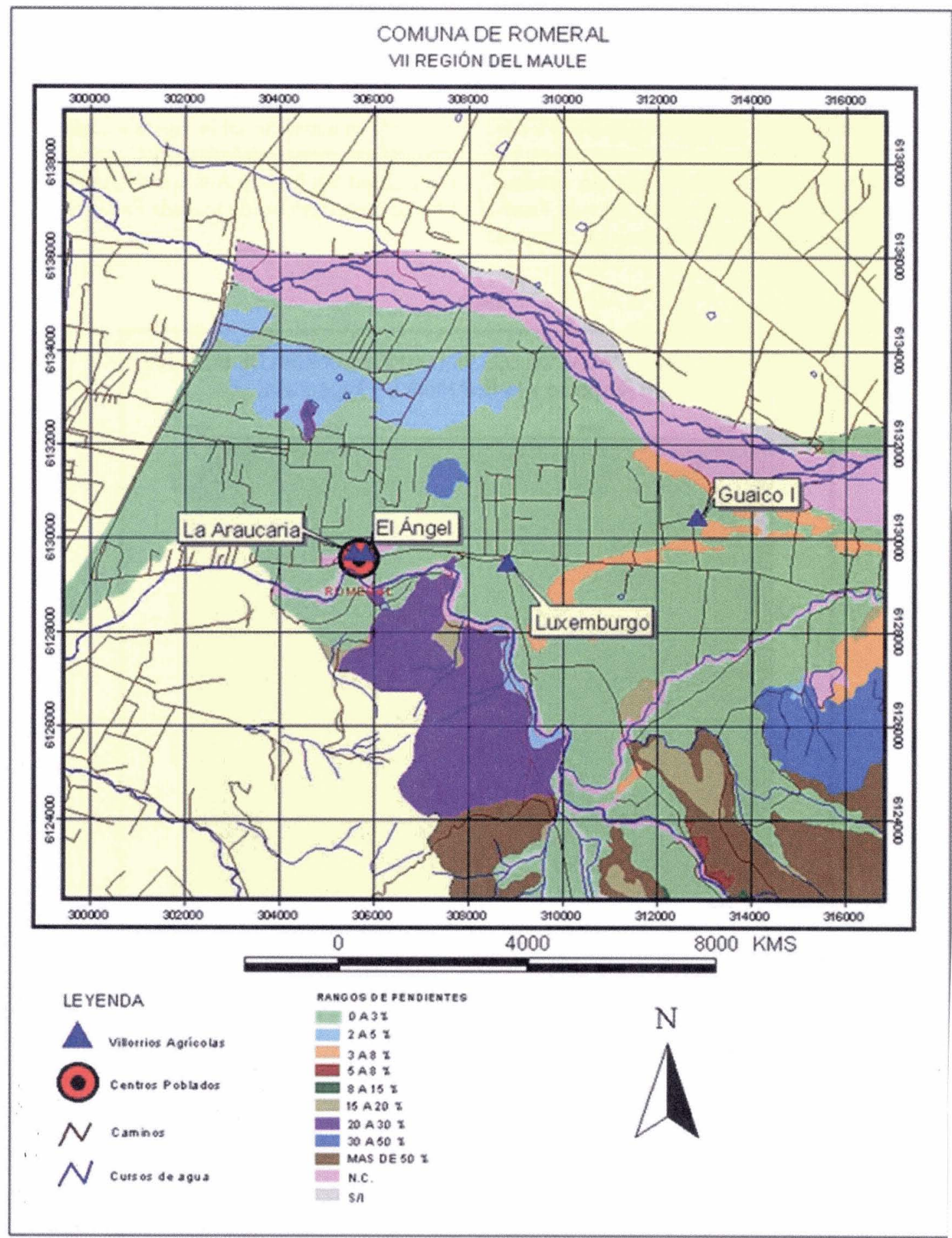

Fuente: Elaboración Retamales, C. En base a cartografía IGM. 
Mapa $N^{\circ}$ 6. Localización de los Villorrios de Romeral con respecto al Uso Potencial del Suelo.

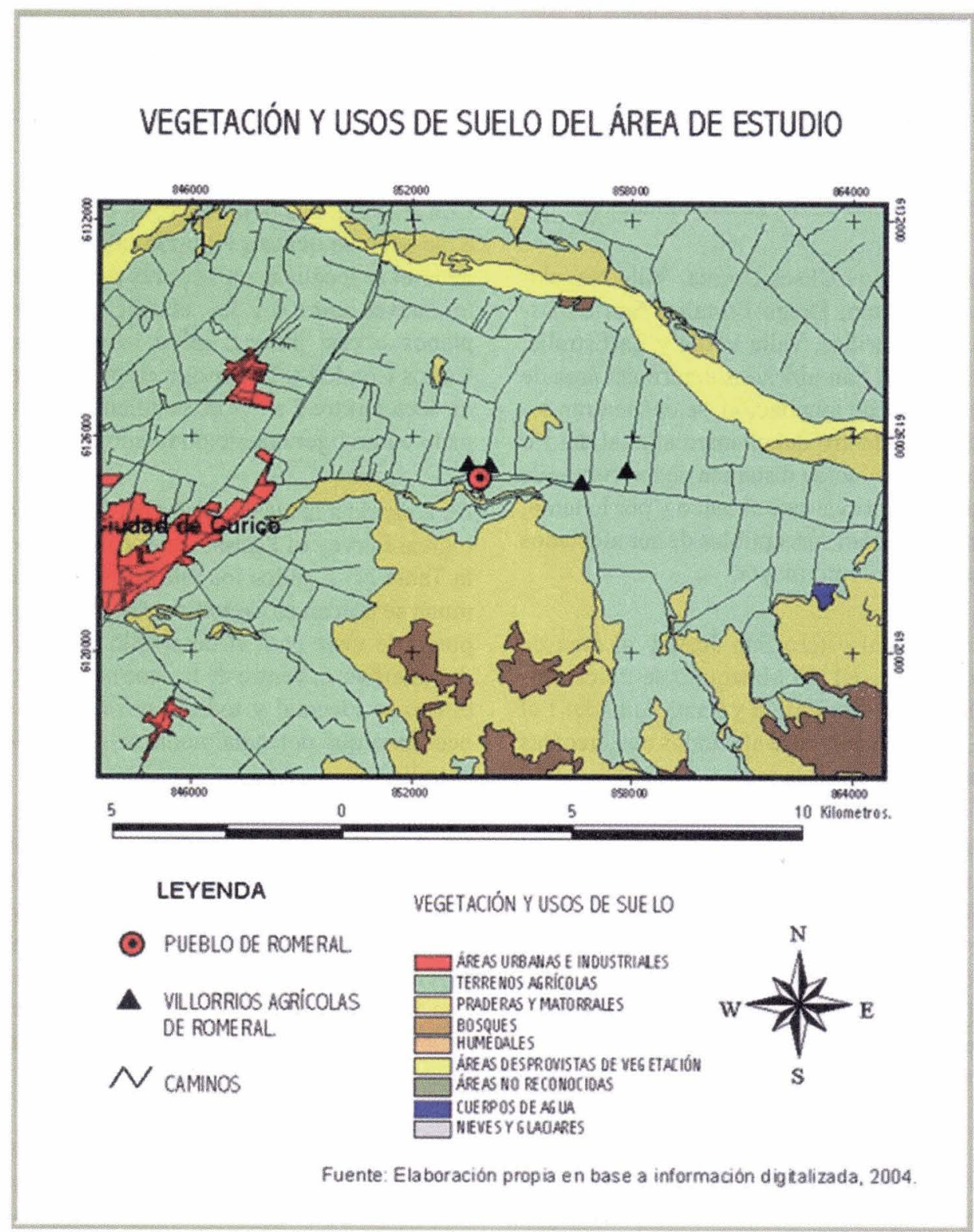

Fuente: Elaboración Wiederhold, E. Según información SINIA.

En el sector de Villa Prat hay dos zonas de especial atención; la primera se relaciona a los terrenos entre el pueblo de Villa Prat y el río Mataquito, sector conocido como La Isla, que corresponde a una terraza fluvial inferior y en donde el estudio identifica meandros abandonados subparalelos al cauce principal que hacen este lugar susceptible de ser inundado. La segunda zona se refiere a los cursos de agua secundarios que bajan desde la serranía, los cuales han sido clasificados como de alto peligro de remoción en masa (PRC, anexo Factibilidad Sanitaria y Análisis de Aguas Lluvias de la Comuna de Sagrada Familia). 
El Mapa $\mathrm{N}^{0} 7$ da cuenta de la localización de los villorrios agrícolas en relación a la Red hídrica de la comuna y a las áreas de restricción identificadas en el Plan Regulador Comunal; de aquí se desprende que los villorrios La Cruz, Corral de Piedra, Nuevo Amanecer y Sanatorio están localizados dentro del área definida como de riesgo de inundación.

Los villorrios Ulises Correa, Villa Nogalada, La Unión, Diego Portales, San Sebastián, Higuerillas, Valle Verde y La Estrella, si bien no están ubicados dentro del área de alto riesgo de inundación, se encuentran localizados dentro del abanico aluvial del río Lontué a reducida distancia de los cursos de agua que forman este abanico y por lo tanto, también serían susceptibles de ser afectados por algún evento mayor.

Próximos al estero San Juan y al área de inundación del río Mataquito se ubican los villorrios Santa Emilia y Santa Ana (del 1 al 4), que podrían verse afectados con crecidas mayores de estos cursos.

Prácticamente en el área de influencia del estero San José se localizan los villorrios La Victoria 1 y 2. En general, la mayor parte de los villorrios agrícolas de esta área están localizados en las proximidades de cursos de aguas, encontrándose que solo Villa Las Delicias, Padre Hurtado y San José de Peteroa se ubican a más de 1 kilómetro del curso de agua más cercano.

Especial atención reviste la localización de los Villorrios Carlos Condell y El Bosque, que si bien no se encuentran en el área de alto riesgo de inundación, podrían verse afectados por eventos de remoción en masa de cauces pequeños, en periodos de alta intensidad de las lluvias.
En cuanto a la topografía, Sagrada Familia en general no presenta alturas superiores a los $1000 \mathrm{mt}$. La mayor parte de la comuna corresponde a terrenos planos o con leves ondulaciones que no sobrepasan los 500 metros por sobre el nivel del mar.

Con respecto a la pendiente, en el mapa $\mathrm{N}^{\circ}$ 8 , se observa que los villorrios agrícolas en general se localizan en sectores de pendientes suaves, entre 0 y $3 \%$, clasificados como planos o casi planos, salvo los villorrios Carlos Condell y El Bosque emplazados en un sector entre 2 a $5 \%$ de pendiente, catalogado como ligeramente ondulado.

De acuerdo a la clasificación del State Geological Survey of Kansas, que se muestra en la Tabla $\mathrm{N}^{\mathrm{o}} 1$, todos los villorrios de la comuna se ubican en sectores aptos desde este punto de vista para el desarrollo de actividades urbanas, dentro de las que se incluyen el uso residencial y toda la infraestructura necesaria que potencialmente se podría desarrollar.

Finalmente, la aptitud de uso del suelo de los terrenos en donde se emplazan los villorrios es otro aspecto del medio físico importante de considerar, dada la normativa vigente para la conformación de villorrios que establece que estos asentamientos no deben localizarse en terrenos que presenten aptitud agrícola.

$\mathrm{Al}$ respecto y tomando como referente la información del SINIA, mostrada en el mapa $\mathrm{N}^{\circ}$ 9, se detecta que todos los villorrios de Sagrada Familia están emplazados en lo que el Sistema Nacional de Información Ambiental clasifica como suelos de aptitud agrícola. 
Mapa $\mathbf{N}^{\circ}$ 7. Localización de Villorrios de Sagrada Familia con respecto a la Red Hídrica.

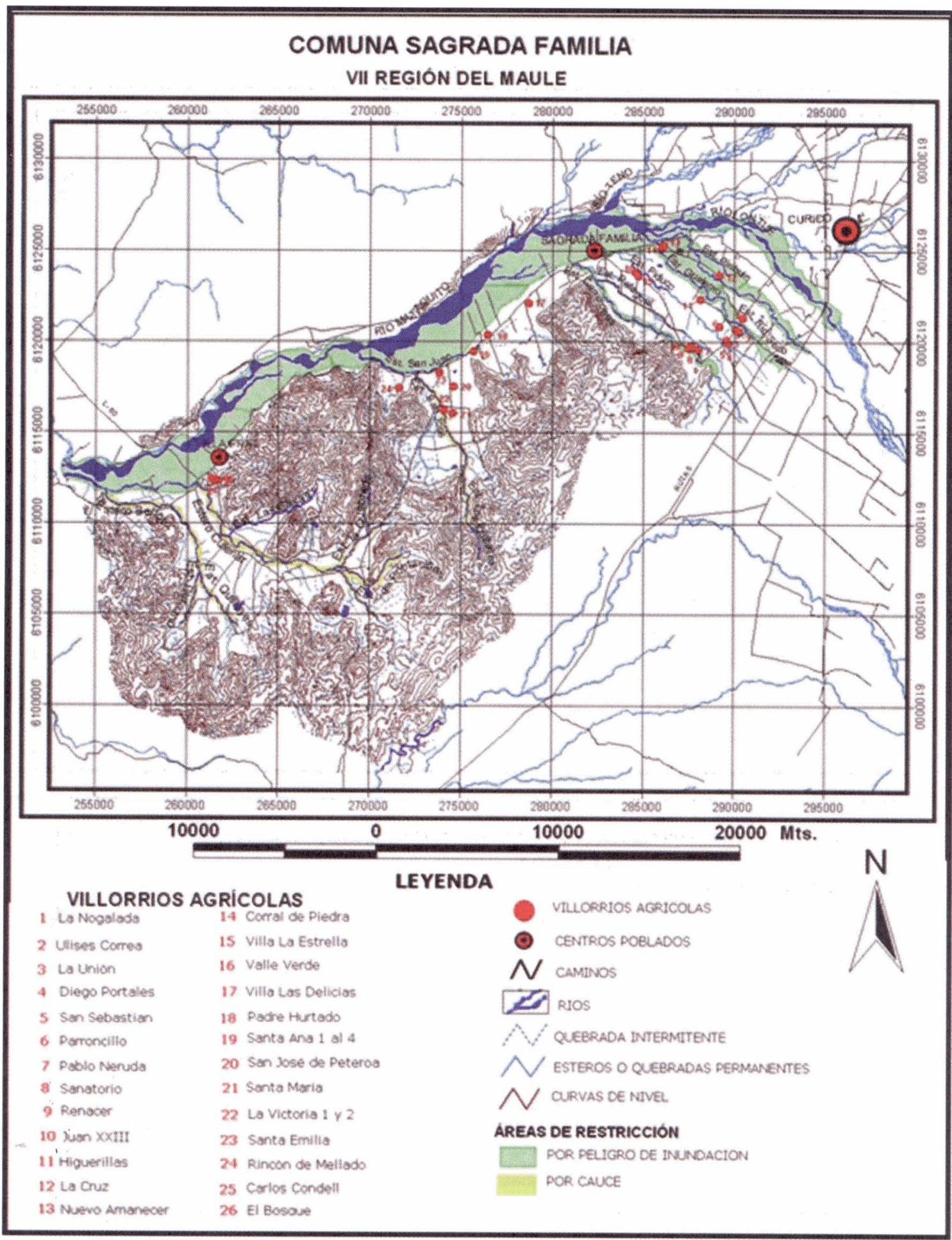

Fuente: Elaboración Retamales C. En base a información Plan Regulador Comunal (2005) 
Mapa $\mathbf{N}^{\circ}$ 8. Localización de los Villorrios de Sagrada Familia con respecto a las Pendientes.

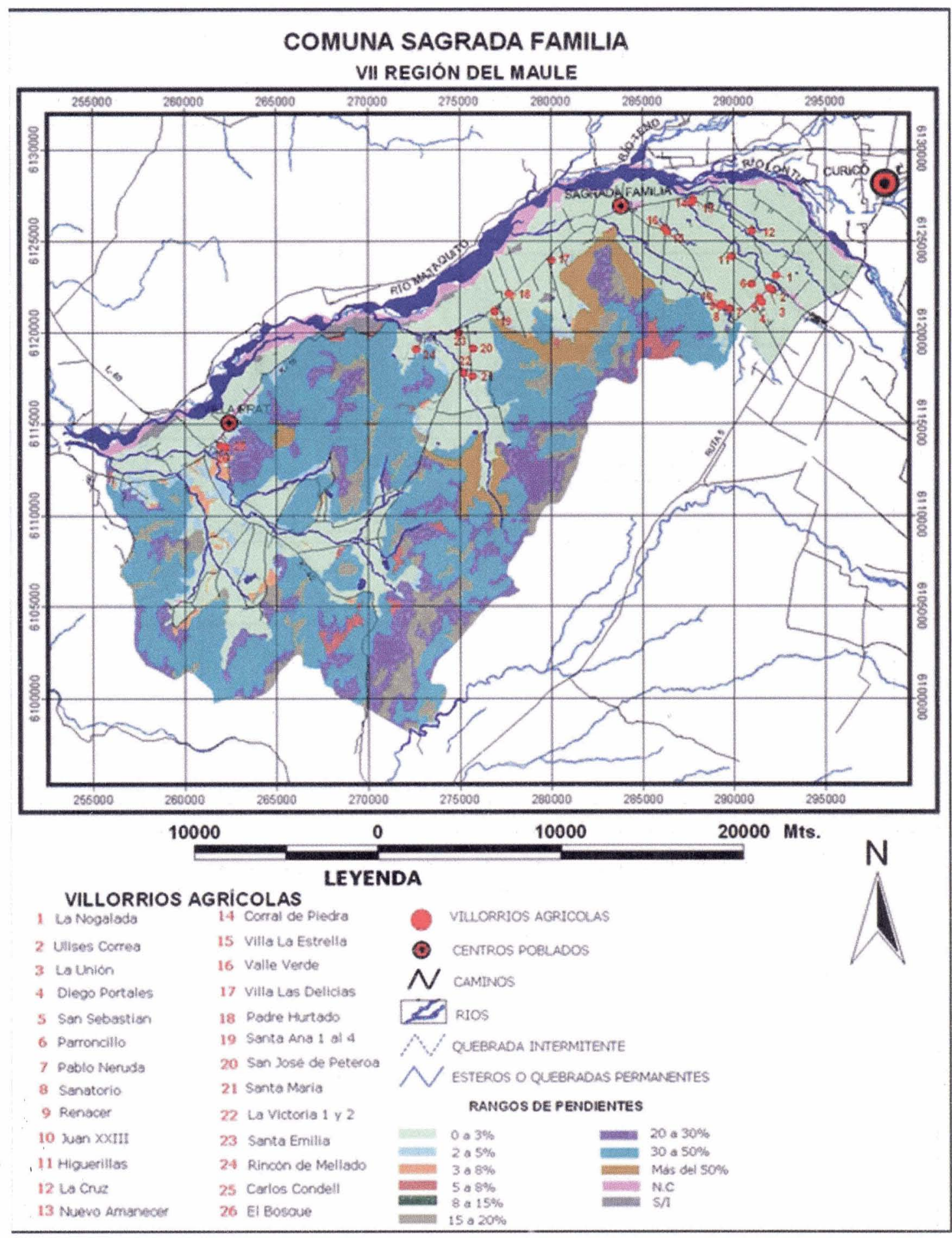

Fuente: Elaboración Retamales, C. En base a Cartografía IGM. 
Mapa No 9. Localización de los Villorrios de Sagrada Familia con respecto al Uso Potencial del Suelo.

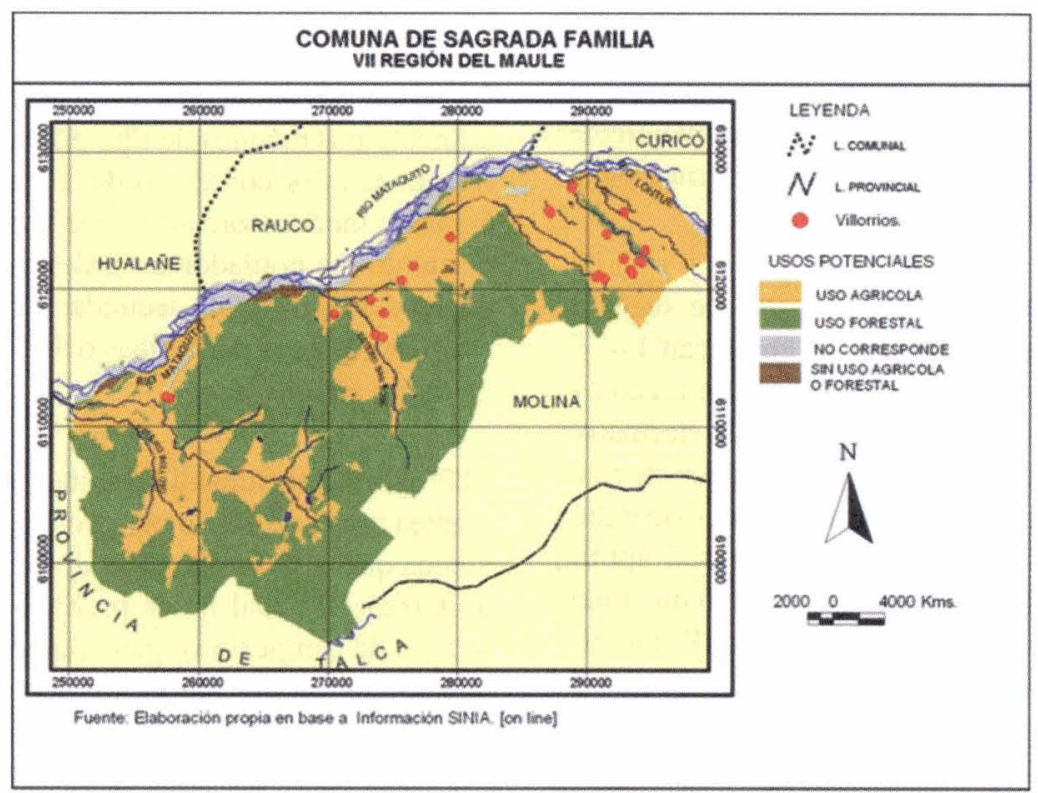

Fuente: Elaboración propia en base a Información del Sistema Nacional de Información Ambiental (SINIA)

\section{DISCUSIÓN DE RESULTADOS}

\section{Problemas derivados de la localización espacial}

Un problema común en las tres comunas corresponde a la cercanía de un número importante de villorrios a cursos de aguas naturales o artificiales, lo que se traduce en serios problemas de habitabilidad en los asentamientos que pueden ser afectados por inundaciones en época de crecida de los cursos de agua.

En Curicó, estos problemas son causados por el río Teno que afecta a cinco villorrios; el estero Quetequete a dos villorrios; el estero Chequenlemu a tres villorrios y el estero Potrero Grande a cuatro villorrios del sector. En Romeral, el riesgo lo presenta preferentemente el estero Guaiquillo que se encuentra próximo a tres villorrios, en tanto el desborde de canales de regadío podría perjudicar a uno de ellos. En Sagrada Familia por su parte, el riesgo de inundación deriva del río Mataquito (que se forma por la confluencia de los ríos Teno y Lontué). El río Lontué puede afectar a 4 villorrios; El estero San Juan en las proximidades a su confluencia con el estero San José y dentro del área de inundación del río Mataquito, afectaría a 3 villorrios. Además, existe una serie de esteros y cauces pequeños que se ubican en el sector oriental de la comuna que también pueden afectar a algunos villorrios en períodos de alta intensidad de precipitaciones, provocando remociones en masa; mientras que al poniente el sector más vulnerable es La Isla, por influencia del río Mataquito.

En cuanto a la localización de los villorrios con respecto a la pendiente, en las tres comunas los villorrios están localizados en rangos de pendiente óptimos para el desarrollo de infraestructura urbana, salvo dos villorrios en la comuna de Curicó (Nuevo Amanecer y Villa Cordillera), y dos villorrios de la comuna de Sagrada Familia (Carlos Condell y El Bosque), los cuales se emplazan 
en terrenos que presentan limitaciones para la construcción de infraestructura urbana; sin embargo, estas restricciones presuponen el uso del terreno sin modificación de las pendientes, por lo tanto, mediante recursos técnicos es posible modificar las pendientes y desarrollar las actividades mencionadas anteriormente.

Finalmente, la aptitud de uso de suelo de los terrenos en donde se emplazan los vi1lorrios es otro aspecto del medio físico importante de considerar, dada la normativa vigente que regula la conformación de estos asentamientos y que establece que no deben situarse en terrenos que presenten aptitud agrícola, pese a lo cual se detectó que todos los villorrios de las comunas de Romeral y Sagrada Familia se localizan en suelos de aptitud agrícola y que 22 villorrios de los 29 existentes en la comuna de Curicó están en la misma situación.

Lo anterior implica, que la normativa que restringe el uso residencial en áreas de aptitud agrícola y riesgos de inundación, no se ve respaldada por la realidad que se observa en el emplazamiento de los villorrios en general. Esta situación evidencia que los terrenos para el establecimiento de villorrios en esta comuna han sido escogidos en función de su menor valor relativo, dejando fuera de consideración la problemática ambiental, aunque al respecto cabría cuestionar el criterio con que se otorga el certificado de habitabilidad de los sitios en el trámite inicial de la formación de los villorrios que autoriza el cambio de uso del suelo (de rural a residencial).

\section{CONCLUSIONES}

Los resultados del estudio demuestran que gran parte de los nuevos asentamientos rurales surgidos en el contexto de la Globalización y Modernización productiva en las comunas seleccionadas de la Región del Maule, se localizan espacialmente en áreas de riesgo de inundación provocado por des- bordes de ríos, esteros y canales de regadío, lo cual afecta las condiciones de habitabilidad de estos asentamientos.

Dicha situación puede explicarse fundamentalmente por razones de tipo económico referidas al valor comercial del suelo, que en áreas de modernización tiende a elevarse y por tanto los pobladores rurales quedan reducidos a un mercado secundario de tierras, situadas en áreas periféricas o áreas de riesgo como en este caso.

El Programa de Subsidio Habitacional Rural plantea como requisito para postular a la vivienda que se debe acreditar derechos sobre un terreno, lo cual no es problema cuando se trata de campesinos, pero cuando son los pobladores rurales sin tierras los postulantes necesariamente deben recurrir a la compra de ellos, surgiendo el problema que se señala al respecto, lo cual adquiere mayor dimensión cuando se trata de terrenos para formar nuevos asentamientos poblados, que requieren un mínimo de 30 familias. Esta situación estaría propiciando un proceso de segregación socio-espacial en el campo chileno, replicando lo que sucede en ciudades, como lo señala SABATINI (2000). A su vez, esta realidad contradice las disposiciones legales que señalan explícitamente que las áreas de riesgo deben quedar excluidas para el uso residencial, lo cual debe ser refrendado por la Comisión Mixta que autoriza el cambio de uso de Rural a Residencial.

La misma disposición rige para la ocupación de suelos de aptitud agrícola con el objeto de preservarlos para la agricultura, pero el estudio demuestra que también esta normativa es vulnerada en la práctica, por cuanto gran parte de los villorrios se ubican en suelos con esta aptitud, lo cual no constituye un problema directo para los pobladores de estos asentamientos, pero sí para la localidad rural donde se emplazan, ya que reduce las áreas de actividad productiva, lo que a la larga restringe también las perspectivas de futuros empleos para estos pobladores al re- 
ducirse el espacio productivo por ocupación con fines residenciales.

Considerando las tres variables de análisis, puede afirmarse entonces que dos de ellas, esto es, la Red hídrica y la Aptitud del suelo son significativas para explicar las condiciones físico-ambientales negativas de localización de los villorrios agrícolas del área de estudio, en tanto la variable Pendiente no genera problemas al respecto, por cuanto estos asentamientos en general se localizan en terrenos planos, aptos de este punto de vista para el uso residencial, como lo señala el Sistema Nacional de Información Ambiental (SINIA).

Como reflexión general puede plantearse que si dentro del proceso de modernización productiva inserto en la Globalización de la Economía, las áreas rurales han sido valorizadas para usos productivos y usos residenciales, debiera prevenirse la situación descrita mediante una Política de Asentamientos Rurales que considere la normativa para regular los usos del suelo con fines residenciales, cuando se trata especialmente de formar nuevos asentamientos poblados habitados por pobladores de bajos ingresos del sector rural, y cuyo financiamiento es estatal, con el objeto de crear hábitat con condiciones adecuadas de habitabilidad y evitar con ello la contradicción entre áreas productivas generadoras de riqueza y áreas residenciales que afectan la calidad de vida de sus residentes, los que paradojicamente se desempeñan como trabajadores temporeros en las primeras. De esta forma, se conjugaría la relación entre crecimiento económico y desarrollo rural en los campos chilenos.

De igual forma, se reduciría en parte la problemática planteada en la Teoría del Dualismo Intra-rural (SILI, 2002), haciendo partícipes del desarrollo a los pobladores rurales sin tierras que residen en los villorrios agrícolas, lo cual y de acuerdo a lo señalado por LEANDER (2001), es una tarea pendiente vinculada a una Política de Ordenamiento Territorial específica para las áreas rurales, y no como sucede en la actualidad donde es la Ley General de Urbanismo y Construcciones (Art. 55) la que dicta las normas al respecto.

Finalmente, cabe señalar que de acuerdo a los objetivos enunciados por la Conferencia de las Naciones Unidas Hábitat II (Estambul, 1996), la Política de Subsidio habitacional rural (Título II) del MINVU, ha conducido efectivamente a mejorar las condiciones de vida de los pobladores rurales sin tierra, al facilitarles el acceso a la vivienda y a los servicios básicos asociados, pero ello es condición necesaria, pero no suficiente para resolver el problema de la pobreza rural, por cuanto la creación de los nuevos hábitat rurales adolece de los problemas señalados.

\section{BIBLIOGRAFÍA}

ARMISÉN, J. P. 2004. Satisfacción Residencial y Calidad de Vida en los Villorrios Agrícolas. Comuna de Curicó, VII Región del Maule: Memoria para optar al título de Geógrafo, Facultad de Arquitectura y Urbanismo, Universidad de Chile. Inédito. 132 pp.

BENGOA, J. 2007. Territorios Rurales: Movimientos sociales y desarrollo territorial rural en América Latina. Centro Latinoamericano para el Desarrollo Rural (RIMISP). Editorial Catalonia. Santiago, Chile. 613 pp.

BERNAL-MEZA, R. 2000. Sistema mundial y MERCOSUR. Globalización, Regionalismo y Políticas Exteriores Comparadas. Ed. Nuevo Hacer, B. Aires, Argentina.

BOSQUE, J. 1976. Percepción, Comportamiento y Análisis Geográfico. Universidad Complutense de Madrid, España.

CEPAL - ECLAC. 2003. La Pobreza rural en América Latina: Lecciones para una reorientación de las políticas. Serie Seminarios y Conferencias. Santiago, Chile. 
COLAVIDAS \& SALAS, 2005. Programas de Doctorado Conjunto. Madrid, España.

DIPUC, 2008. Habitabilidad en la vivienda: Unificación de parámetros, estándares y requerimientos de calidad. Taller Departamento de Investigación Pontificia Universidad Católica de Chile. Santiago.

ECHENIQUE, J. 2001. Ruralidad en Chile: Evolución y proyecciones. En Perspectivas para la Ruralidad en Chile. Editorial Universidad de Santiago. Santiago, Chile, pp. 51-74.

FERRANDO, F. 2003. En torno a los desastres "naturales". Tipología, Concepto y Reflexiones. En revista INVI No 47. Facultad de Arquitectura y Urbanismo, Universidad de Chile, Santiago. pp. 13-29.

HERMOSILLA, E. 1994. El Hábitat Rural es una prioridad del MINVU. En Vivienda y Participación. Ministerio de Vivienda y Urbanismo. Santiago, Chile, pp. 2-5.

HERZER \& DI VIRGILIO. 1996. Buenos Aires: Pobreza e Inundación. Revista EURE $N^{\circ}$ 67, Volumen XXII. Santiago; Chile, pp. 65-80.

ILUSTRE MUNICIPALIDAD DE SAGRADA FAMILIA, 2005. Plan Regulador Comunal. Anexo Factibilidad Sanitaria y análisis de Aguas Lluvias.

INSTITUTO DE LA VIVIENDA (INVI). 2004. Bienestar Habitacional. Guía de Diseño para un Hábitat Residencial Sustentable. Facultad de Arquitectura y Urbanismo. Universidad de Chile. 123 pp.

INSTITUTO GEOGRÁFICO MILITAR (IGM). Cartografía Regular Digital comunas de Curicó, Romeral y Sagrada Familia. Santiago, Chile.

INSTITUTO NACIONAL DE ESTADíSTICAS. 2002. Censo Nacional de Población y Vivienda. Santiago, Chile.
INSTITUTO NACIONAL DE ESTADÍSTICAS. 2007. Censo Nacional Agropecuario. Santiago, Chile.

LARRAÍN, P. \& P. SIMPSON. 1994. Percepción y prevención de catástrofes naturales en Chile. Ediciones Universidad Católica de Chile. Santiago. 140 pp.

LEANDER, M. 2001. Nuevos conceptos para la ruralidad chilena. En Perspectivas de la Ruralidad en Chile. Editorial Universitaria de Santiago, Chile, pp. 15-24.

LEWIS, W. A. 1954. Desarrollo Económico con oferta ilimitada de mano de obra. Traducción Manuel Sánchez, 1960. México. 629 pp.

MÉNDEZ, R. 2003. "Globalización, Redes y Nuevos contrastes territoriales". En un mundo por descubrir en el siglo XXI. Real Sociedad Geográfica. Madrid, España.

MINISTERIO DE OBRAS PÚBLICAS Y TRANSPORTE (MOPT), 1993. Guía para la Elaboración de Estudios del Medio Físico, Madrid, España.

MINISTERIO DE VIVIENDA Y URBANISMO, 1994. El hábitat rural: Una prioridad del MINVU. En Debate; Las villas rurales. En Revista Vivienda - Participación Progresiva $\mathrm{N}^{\circ}$ 5, Volumen 2, $41 \mathrm{pp}$.

RIFFO, M. \& C. RETAMALES. 2005. Caracterización del Proceso de Re-asentamiento de la Población Rural vinculado a la Globalización de la Economía en la Región del Maule. En Anales de la Sociedad Chilena de Ciencias Geográficas. Santiago, Chile, pp. 279-291.

RIFFO, M. \& C. RETAMALES. 2007. Dinámica de cambios en el patrón de asentamientos de la población rural: Región del Maule. Revista Investigaciones Geográficas 39: 62-90. 
ROMERO, J. \& J. FARINÓS. 2004. Los territorios rurales en el cambio de siglo. En Geografía Humana: Procesos, Riesgos e Incertidumbres en un mundo globalizado. Editorial Ariel. Barcelona, España.

SABATINI, F. 2000. Reforma de los mercados de suelo en Santiago de Chile. Efectos de los precios de la tierra y la segregación residencial. Revista EURE N ${ }^{\circ}$ 77, Santiago, Chile. pp. 53-67.

SILI, M. 2002. Del Enfoque Agrario al Enfoque Rural. Ideas y Conceptos para construir una nueva ruralidad. En Revista Universitaria de Geografía. Universidad Nacional del Sur. Bahía Blanca, Argentina, pp. 71-90.

SISTEMA NACIONAL DE INFORMACIÓN AMBIENTAL (SINIA) [en línea]. Cartografía de Vegetación y uso de Suelo actual, [consulta junio del 2005] disponible en:http://www.sinia.cl/1292/channel.html

TASVILLE, S.; M. FONSECA.; L. RODRÍGUEZ. 2002. Procedimientos y cambios de uso de suelo en el sector rural de la Sexta Región. En Vivienda y Calidad de Vida en los Asentamientos rurales. Red XIV - E de Cyted - Habyted. Puerto Montt, Chile. pp. 188-196.

WIEDERHOLD, E. 2004. Caracterización y Perspectivas de Consolidación de los Villorrios Agrícolas. Comuna de Romeral, VII Región del Maule: Memoria para optar al título de Geógrafo, Facultad de Arquitectura y Urbanismo, Universidad de Chile. Inédito. $115 \mathrm{pp}$. 